\title{
Fully Automated Screening of a Combinatorial Library to Avoid False Positives: Application to Tetanus Toxoid Ligand Identification
}

\author{
María C. Martínez Ceron, * Lucía Ávila, Silvana L. Giudicessi, Juan M. Minoia, Matías Fingermann, \\ Silvia A. Camperi, Fernando Albericio, and Osvaldo Cascone*
}

Cite This: ACS Omega 2021, 6, 18756-18762

Read Online

\section{ACCESS | Lill Metrics \& More | 回 Article Recommendations ｜（） Supporting Information}

ABSTRACT: Peptide ligands are widely used in protein purification by affinity chromatography. Here, we applied a fully automated two-stage library screening method that avoids false positive peptidyl-bead selection and applied it to tetanus toxoid purification. The first library screening was performed using only sulforhodamine (a fluorescent dye), and fluorescent beads were isolated automatically by flow cytometry and discarded. A second screening was then performed with the rest of the library, using the target protein (tetanus toxoid)-rhodamine conjugate. This time, fluorescent beads were isolated, and peptide sequences were identified by matrix-assisted laser desorption/ionization tandem mass spectrometry. Those appearing with greater frequency were synthesized and immobilized on agarose to evaluate a range of

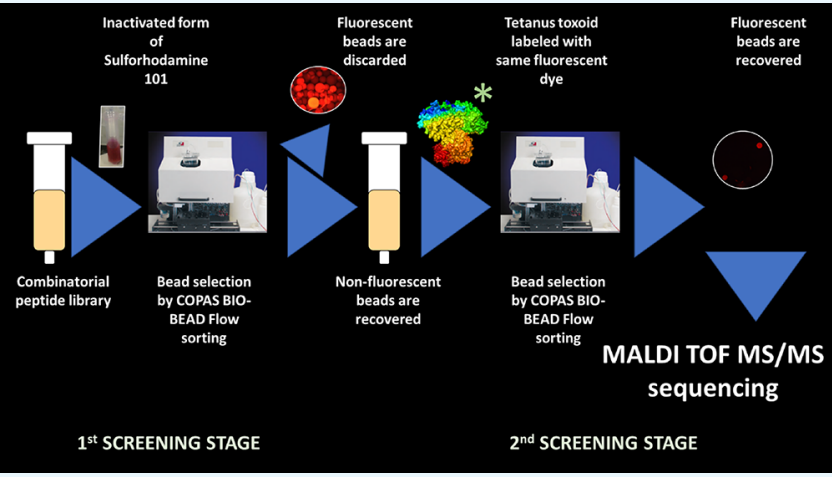
chromatographic purification conditions. The affinity matrix PTx1agarose (Ac-Leu-Arg-Val-Tyr-His-Gly-Gly-Ala-Gly-Lys-agarose) showed the best performance when 20 mM sodium phosphate, $0.05 \%$ Tween 20 , pH 5.9 as adsorption buffer and $100 \mathrm{mM}$ Tris- $\mathrm{HCl}, 100 \mathrm{mM} \mathrm{NaCl}, \mathrm{pH} 8.0$ as elution buffer were used. A pure tetanus toxoid ( $\mathrm{Ttx}$ ) was loaded on a chromatographic column filled with the PTx1 matrix, and 96\% adsorption was achieved, with a $K_{\mathrm{d}}$ of $9.18 \pm 0.07 \mathrm{nmol} / \mathrm{L}$ and a $q_{\mathrm{m}}$ of $1.31 \pm 0.029 \mu \mathrm{mol} \mathrm{Ttx} / \mathrm{mL}$ matrix. Next, a Clostridium tetani culture supernatant treated with formaldehyde (to obtain the toxoid) was applied as a sample. The sodium dodecyl sulfate polyacrylamide gel electrophoresis analysis showed a band, identified by electrospray ionization mass spectrometry as the Ttx, that appeared only in the elution fraction, where an S-layer protein was also detected.

\section{INTRODUCTION}

Here, we propose a fully automated two-stage one-bead-onepeptide library screening. To this end, a fluorescent dye was first used to discard peptidyl-beads with affinity for the label, and then, the rest of the library was used for a second screening with the target protein labeled with the same dye. Positive beads obtained by this two-step screening process were thus selected, and their peptide was sequenced. The tetanus toxoid (Ttx) was selected as the target protein. The use of the tetanus toxin $(\mathrm{Tt})$ as the target protein for the screening process is not recommended because, as a biohazard, special equipment and infrastructure would be required. The Ttx, used to produce tetanus vaccines, is prepared by inactivation of the $\mathrm{Tt}$ with formaldehyde. ${ }^{1}$ Traditional Ttx purification is achieved by a two-step salting out process followed by ultrafiltration. ${ }^{2-4}$ Although this low-cost methodology has been used for many decades by manufacturers of most of the antitetanus vaccines, it is a laborious process that gives low yields. Moreover, the process is also prone to achieving low-quality products, possibly related to under optimal purification. An increase in Ttx purity would reduce the adverse effects of vaccines and allow a boost in dose, thereby enhancing immunization. ${ }^{5}$ The use of a low-cost affinity matrix that allows for Ttx purification directly from the chemically inactivated clarified culture supernatant would thus be advantageous. Operator exposure to the toxin would be reduced, other contaminants would be eliminated from the sample, and fewer samples would be used for the precipitation with ammonium sulfate, thus making the process less expensive. For all these reasons, vaccine production could be made safer without greatly increasing costs.

The use of immobilized peptide ligands instead of antibodies for protein purification by affinity chromatography allows access to matrices that are less susceptible to degradation by physical, chemical, or biological agents. Peptide ligands can be

Received: April 5, 2021

Accepted: July 2, 2021

Published: July 16, 2021 
tailored to avoid sequences susceptible to protease degradation or to improve their affinity and selectivity. Furthermore, they can be produced by large-scale good manufacturing practices (GMPs). ${ }^{6}$ Finally, peptide ligand matrices allow the use of more astringent elution or regeneration conditions than those based on proteins. ${ }^{7-9}$ Peptide ligands suitable for protein purification can be found by screening combinatorial peptide libraries, an approach in which thousands of molecules can be evaluated in one step. First, peptide libraries are synthesized using divide-couple-recombine (DCR) solid-phase peptide synthesis (SPPS). ${ }^{10,11}$ This method assures the production of a combinatorial library with a "one-bead one-compound" distribution. The library is then screened to find peptides with affinity for the target protein. Generally, this protein is first labeled with biotin or a fluorescent dye as the reporter group. The latter allows screening automation using the complex object parametric analyzer and sorter (COPAS) BIOBEAD flow sorting equipment (Union Biometrica), which has the capacity to analyze and sort fluorescent beads. ${ }^{12}$ Those peptidyl-beads that adsorb the labeled protein are identified by their fluorescence and are isolated. Afterward, each bead is washed, and the peptide is separated for sequence analysis by tandem mass spectrometry (MS/MS). False positive beads are commonly selected, despite using nonionic detergents and blocking agents such as gelatin or powdered milk. ${ }^{13,14}$ When hydrophobic fluorescent dyes are used as labels, peptides with a high content of hydrophobic amino acids may interact with the dye. ${ }^{15}$ In general, peptidyl-beads interacting directly with the fluorescent dyes present bright homogeneous fluorescence, while those interacting with the protein moiety of the conjugate have a characteristic halo appearance, with higher fluorescence intensity at the edges of the bead and lower fluorescence in the core. Nevertheless, the difference in fluorescence intensity depends on the type of fluorescent dye. Furthermore, an expert eye is needed to detect subtle differences. ${ }^{16}$ We previously designed a "two-stage screening method" 17 using bovine serum albumin (BSA) as the model protein to avoid the selection of unsuitable peptides with affinity for the fluorescent label rather than for the target protein. That methodology involves a manual step.

The aim of this work was to develop a fully automated twostage library screening process to find a peptide ligand for Ttx purification and thus contribute to making safer vaccines.

\section{RESULTS AND DISCUSSION}

2.1. Ligand Peptide Identification by Library Screening and MALDI-TOF MS/MS. Figure 1 summarizes the twostage one-bead-one-peptide library screening strategy developed.

Dyes with maximum emission in red are selected because ChemMatrix resin beads exhibit a significant intrinsic fluorescence with maximum emission in green (Figure S1A). This is a problem when screening against green fluorescentlabeled proteins. ${ }^{8,18}$ Although Lavoie et al. ${ }^{19}$ reported intrinsic fluorescence in its screening conditions (Alexa Fluor 488 dye to label Chinese hamster ovary host cell proteins and Alexa Fluor 546 dye to label human IgG and incubated with a peptidyl ChemMatrix library), we found that this resin showed a very small autofluorescence, under the present working conditions (Figure S1B), as was reported by Comellas et al. ${ }^{20}$ Also, beads must be hydrated with buffer to avoid drying when inspected under a fluorescence microscope. Dry beads are fluorescent, and positive beads cannot be distinguished from

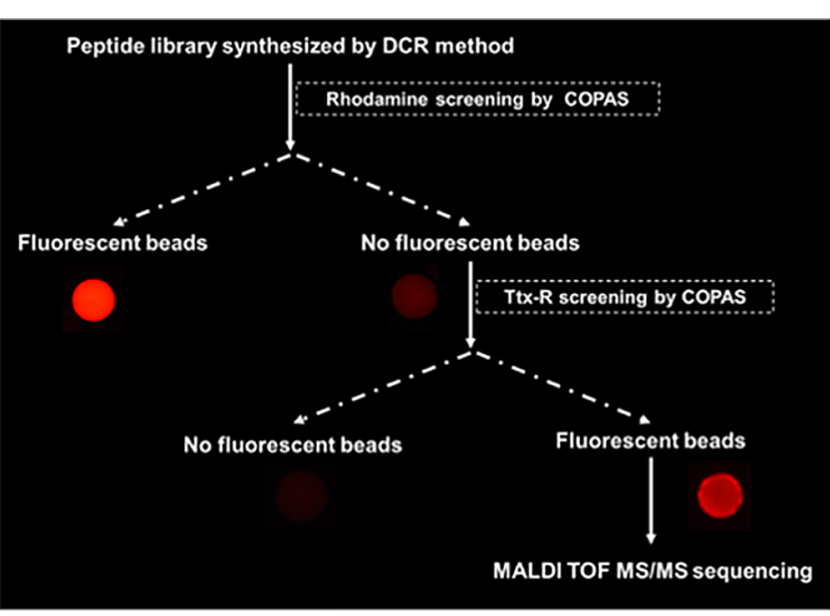

Figure 1. Automated two-stage peptide library screening strategy.

negative beads. When the beads are swollen in buffer, they exhibit a significant intrinsic fluorescence with maximum emission in green but not in red.

A sulforhodamine 101 acid chloride fluorescent dye conjugated to the tetanus toxoid allows the use of COPAS BIOBEAD sorting to sort OBOC peptidyl libraries. However, manual inspection under a fluorescence microscope shows the presence of false positive beads, with a bright homogeneous fluorescence (Figure S1C) and positive ones, with a characteristic halo appearance (Figure S1D). To avoid this manual inspection, a two-stage screening was performed. First, the sulfonyl chloride group of sulforhodamine 101 acid chloride was converted to the corresponding sulfonamide (rhodamine or $\mathrm{Rh}$ ) by ammonium vapor treatment (Figure S2) and used as the dye for the first library screening. Sixty thousand beads were used for the first screening. Those that showed an intense fluorescence (approximately 7.8\%), with affinity for the fluorescent dye (Rh), were isolated. Gating and sorting regions were defined for sorting beads on the COPAS based on their time of flight (TOF) to sort uniformly sized beads and red fluorescence intensity (RED) (Figure S3A,B). Fluorescence microscopy showed homogeneous fluorescence (Figure S1C). Their peptides were identified by MALDI-TOF MS but not submitted to the second screening. Table $S 1$ shows the positive sequences obtained, and Figure S4 shows the position frequency for all the amino acids assayed. Phe was the most frequent residue in positions $\mathrm{X} 1, \mathrm{X} 4$, and $\mathrm{X} 5$ and Tyr in $\mathrm{X} 2$, while both residues were observed in $\mathrm{X} 3$. The structure of these two amino acids has aromatic rings. Rhodamine $(\mathrm{Rh})$, with multiple aromatic rings, can bind Phe and Tyr through hydrophobic interactions (Figure S5).

Afterward, the remaining beads were recovered, washed, and conditioned for the second screening with the tetanus toxoidrhodamine conjugate. From the total, a sample of 10 thousand beads were separated using the COPAS, and a total of 781 beads were recovered. Fluorescence microscopy showed that all isolated beads showed a halo-like fluorescence due to the interaction of the target protein with the peptide immobilized in the beads (Figure S1D). This phenomenon has been previously observed by our and other groups. ${ }^{8,16,17,21}$ Finally, the peptides from 47 beads of those 781 beads were released and identified by MALDI-TOF MS analysis (Table S2). The presence of charged and hydrophobic residues may indicate that the binding was through affinity interaction and not only 
through hydrophobic forces (Figure S6). The peptide PTx1 (H-Leu-Arg-Val-Tyr-His-Gly-Gly-Ala-Gly-Gly- $\mathrm{NH}_{2}$ ) was selected for further analysis since it appeared with the highest frequency (4 times) and was consistent with the frequency of amino acids obtained in each position.

2.2. Synthesis of the Peptide Affinity Adsorbent. The ligand PTx1 was synthesized on Rink-amide resin by solidphase chemistry and then immobilized on agarose. The purity of the ligand was over $90 \%$, as determined by HPLC analysis, and the $m / z$ obtained by mass spectrometry analysis (Figures S7 and S8) corresponded to the molecular weight of the peptide synthesized $\left(\left[\mathrm{M}+\mathrm{H}^{+}\right]=1098.84\right)$. The C-terminus Gly was replaced by Lys to allow the peptide to be coupled by its side-chain amine group, while its $\mathrm{N}$-terminus was acetylated, thereby ensuring the same peptide orientation in the agarose support as that in the library bead.

2.3. Chromatographic Performance of the AgarosePeptide Matrix. Samples of the pure Ttx in several buffers and conditions were used to assess the performance of the synthesized matrix. The best result was obtained when the Ttx was loaded in $20 \mathrm{mM}$ sodium phosphate, $0.05 \%$ Tween $20, \mathrm{pH}$ 5.9 , as the adsorption buffer and $100 \mathrm{mM}$ Tris-chloride, 250 $\mathrm{mM} \mathrm{NaCl}, \mathrm{pH} 8.0$, as the elution buffer. Under these conditions, $96 \%$ of the protein was adsorbed and quantitatively eluted.

2.4. Ttx Adsorption Isotherm on PTx1-Agarose. Figure 2 shows the adsorption isotherm of the Ttx on PTx1-agarose,

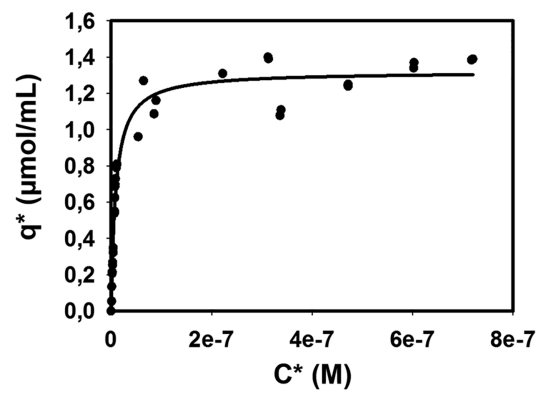

Figure 2. Equilibrium adsorption isotherm for binding of the Ttx to PTx1-agarose. Aliquots of the matrix $(30 \mu \mathrm{L})$ were incubated with samples of $1 \mathrm{~mL}$ of pure Ttx solution at different concentrations in 20 $\mathrm{mM}$ sodium phosphate, $0.05 \%$ Tween 20 , pH 5.9 buffer, in duplicate. The suspension was shaken for $4 \mathrm{~h}$ at $24{ }^{\circ} \mathrm{C}$. The protein concentration was determined following the Bradford technique. ${ }^{22}$ The $K_{\mathrm{d}}$ was $9.18 \pm 0.070 \mathrm{nmol} / \mathrm{L}$ (binding constant $\left(1 / K_{\mathrm{d}}\right)=1.09 \times$ $10^{8} \mathrm{~L} / \mathrm{mol}$ ), and the $q_{\mathrm{m}}$ was $1.31 \pm 0.029 \mu \mathrm{mol} \mathrm{Ttx} / \mathrm{mL}$ matrix.

developed with the pure Ttx in $20 \mathrm{mM}$ sodium phosphate, $0.05 \%$ Tween 20 , pH 5.9 buffer. The isotherm shows a good fit of experimental data to a Langmuir-type isotherm, and it allowed calculation of a maximum capacity $\left(q_{\mathrm{m}}\right)$ of $1.31 \pm$ $0.029 \mu \mathrm{mol} \mathrm{Ttx} / \mathrm{mL}$ matrix and a dissociation constant $\left(K_{\mathrm{d}}\right)$ of $9.18 \pm 0.07 \mathrm{nmol} / \mathrm{L}$ (binding constant $\left(1 / K_{\mathrm{d}}\right)=1.09 \times 10^{8} \mathrm{~L} /$ $\mathrm{mol})$.

2.5. Chromatography of the Formaldehyde-Treated C. tetani Culture Supernatant. The chemically inactivated clarified Clostridium tetani (C. tetani) culture supernatant was conditioned to the equilibration buffer $(20 \mathrm{mM}$ sodium phosphate, $0.05 \%$ Tween 20, $\mathrm{pH} 5.9$ ) and then loaded on the PTx1-agarose column. Figure 3 shows the chromatogram obtained. An important band comes out during the loading and washing steps, which indicates that a good part of the starting material is not adsorbed to the matrix. The Ttx was

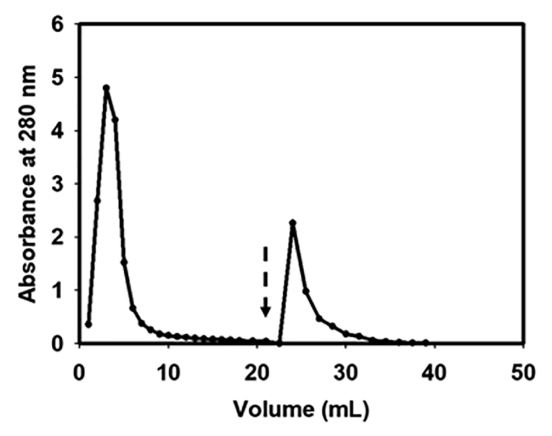

Figure 3. Peptide affinity chromatography of the formaldehydetreated $C$. tetani culture supernatant. The discontinuous arrow indicates the change of buffer.

adsorbed and eluted quantitatively. SDS-PAGE analysis showed that the band corresponding to the Ttx appeared only in the elution fraction (Figure 4). According to the

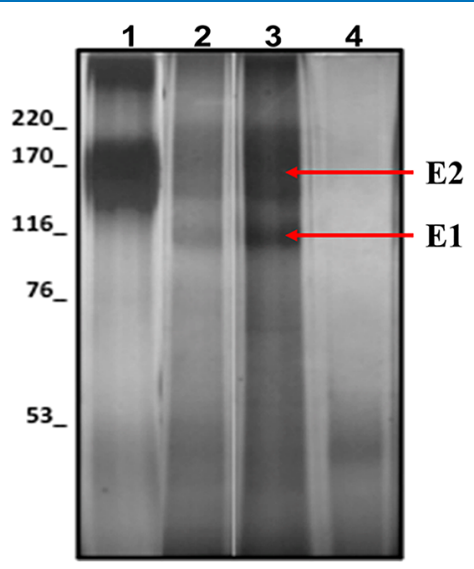

Figure 4. SDS-PAGE (10\%) of formaldehyde-treated C. tetani culture supernatant fractionation. Lane 1: pure Ttx (molecular weight, $\sim 150$ $\mathrm{kDa}$ ). Lane 2: C. tetani supernatant. Lane 3: elution fraction. Lane 4: pass-through fraction. Arrows show the samples selected for identification analysis by mass spectrometry. SDS-PAGE and mass spectrometry showed that band E1 and band E2 were $N$ acetylmuramoyl-L-alanine amidase $(118.6 \mathrm{kDa})$ and the tetanus toxin $(150.6 \mathrm{kDa})$ from C. tetani mixtures, respectively (Table S3).

densitometric quantification, the purity was $80 \%$. Given that the Ttx is a mixture of forms with different degrees of crosslinking, ${ }^{23,24}$ it is consistent that a band as wide as that observed by SDS-PAGE is obtained.

After several Ttx purification cycles, the performance of the matrix did not change. Thus, $\mathrm{N}$-terminus acetylation and $\mathrm{C}$ terminus amidation seem to protect the peptide from the active proteases that might remain after chemical inactivation of the C. tetani culture supernatant. $6,25-29$

To obtain the tetanus toxoid, the bacteria are cultured in liquid broth under anaerobic conditions, and the toxin secreted by $C$. tetani is inactivated by cross-linking for four to six weeks at $37{ }^{\circ} \mathrm{C}$ using $40 \%$ formaldehyde. Bacteria can secrete different proteins into the medium during growth and cell lysis, and the same can also occur during culture in bioreactors. This mixture of the inactivated tetanus toxoid is a nonmalleable crude containing hundreds of $C$. tetani proteins, and the active component is present in varying percentages and sometimes less than the mass of the vaccine. ${ }^{24,30}$ During formaldehyde treatment, intra- and interprotein cross-linking could occur. 
The traditional method for tetanus toxoid purification consists of two stages of precipitation with ammonium sulfate and filtration. ${ }^{31}$ Despite the already mentioned low yields and under optimal purification levels of this technique, its optimization has received little attention until recently. Brgles et al. made use of response surface methodology in order to select the best set of conditions for ammonium sulfate precipitation. ${ }^{4}$ Despite having achieved their goal, they were unable to remove the putative S-layer protein and four other contaminating proteins. Stojićevic et al. ${ }^{1}$ reported the use of interaction hydrophobic chromatography (HIC), chelating chromatography (CC), and immobilized metal ion affinity chromatography (IMAC) for the purification of the Ttx. The best results were obtained when a first tangential ultrafiltration step was used together with HIC (Y\% 50-80\%), similar to those obtained with the traditional method. To perform this chromatography, ammonium sulfate had to be added, which was then removed by diafiltration. The addition of ammonium sulfate was problematic because the protein could precipitate within the column.

The methodology proposed by us avoids the use of ammonium sulfate and achieves a similar yield but in a single step. If a more purified toxoid is needed, a final ammonium sulfate precipitation can be done but at a lower scale, thus reducing the amount of the salt required.

Recently, Möller et al. analyzed the components of tetanus vaccines from Brazil, Bulgaria, Russia, Germany, and India, and they found many proteins in the preparations. ${ }^{32}$ More than 80-90\% corresponded to C. tetani proteins. The tetanus neurotoxin is the major protein in toxoid preparations. However, those authors found that similar amounts of putative $S$-layer proteins were copresent and contributed to protection against $C$. tetani infection; this does not evidence that this protein was cross-linked to the toxoid. This possibility is contradictory. Meanwhile, Brgles et al. ${ }^{4}$ showed that there are no cross-links between proteins when low ammonium sulfate concentrations are used. Other authors ${ }^{33,34}$ reported that when traditional formaldehyde concentration treatment is performed, this interprotein cross-linking could happen. In accordance, we detected other bands in the SDS-PAGE of the affinity-purified toxoid, identifying one of them as the putative S-layer protein. Mass spectrometry of both bands (E1 and E2) revealed that in both cases, the most abundant proteins were S-layer proteins and the Ttx (Table S3).

Beyond this discussion, Möller et al. ${ }^{32}$ also showed that the putative S-layer protein can contribute to the immunogenic potency of the vaccine, which is why no further purification was sought to separate it from the toxoid.

\section{CONCLUSIONS}

The development of a fully automated screening method allowed us, in a first step, to eliminate those peptidyl-beads that showed affinity for the fluorescent tag and, in a second step, to select peptides with affinity for the target protein, in this case the Ttx. This method reduces the selection of false positive beads in an easier way than previous protocols.

Also, one of the peptides synthesized and immobilized on an agarose matrix adsorbed the Ttx and eluted it quantitatively with $80 \%$ purity in a single affinity chromatographic step, starting from the treated with formaldehyde culture supernatant of $C$. tetani. It is important to note that this method is safe and does not require complex equipment since it allows the purification of the Ttx, thus avoiding the manipulation of the dangerous $\mathrm{Tt}$.

\section{EXPERIMENTAL PROCEDURES}

4.1. Materials. Hydroxymethylbenzamide-ChemMatrix (HMBA-CM) resin was donated by Matrix Innovation, Inc. (Montreal, Quebec, Canada). Fmoc-amino acids and $\mathrm{N}$-[(1Hbenzotriazol-1-yl)(dimethylamino)methylene]-N-methylmethanaminium tetrafluoroborate $\mathrm{N}$-oxide (TBTU) were from Peptides International, Inc. (Louisville, KY, USA). 4-(N,Ndimethylamino)pyridine (DMAP), $\alpha$-cyano-4-hydroxycinnamic acid (CHCA), BSA (Fraction V), and sulforhodamine 101 acid chloride were purchased from Sigma-Aldrich (St. Louis, MO, USA). 1,3-Diisopropylcarbodiimide (DIPCDI), N,Ndiisopropylethylamine (DIPEA), and triisopropylsilane (TIS) were supplied by Fluka Chemie AG (Buchs, Switzerland). PD10 desalting columns were from GE Healthcare (Waukesha, WI, USA). The GP Sheath Reagent was from Union Biometrica (Somerville, MA, USA). The pure tetanus toxoid was from INPB-ANLIS Carlos G. Malbrán (Buenos Aires, Argentina). All other reagents were of AR grade.

4.2. Experimental Part. 4.2.1. Synthesis of the Combinatorial Peptide Library. The "one-bead-one-peptide" library was synthesized as described by Kodadek and Bachhawat-Sikder, ${ }^{18}$ using the divide-couple-recombine (DCR) method as per Lam et al. ${ }^{11}$ The library had 248,832 decapeptides XXXXXGGAGG- $\mathrm{NH}_{2}$, where $\mathrm{X}=\mathrm{A}, \mathrm{E}, \mathrm{F}, \mathrm{H}, \mathrm{L}$, $\mathrm{N}, \mathrm{P}, \mathrm{R}, \mathrm{S}, \mathrm{T}, \mathrm{V}$, or Y (variable positions).

4.2.2. Inactivation of Sulforhodamine 101 Acid Chloride. Sulforhodamine 101 acid chloride was converted to the corresponding sulfonamide with ammonium vapor and used for the first library screening. The sulfonyl chloride conversion was necessary to prevent its reaction with the peptidyl-beads. An aliquot of $5 \mathrm{mg}$ of sulforhodamine 101 acid chloride was placed on an open Petri dish inside a drying chamber, together with a flask containing $30 \% \mathrm{NH}_{4} \mathrm{OH}$. The drying chamber was tightly closed and left overnight at room temperature under ammonium vapor. Finally, the dye was dissolved in $\mathrm{MeOH}$ and analyzed by MALDI-TOF MS to confirm its conversion (sulforhodamine 101 acid chloride and its sulfonamide derivative have $\mathrm{MW}=625.15$ and $\mathrm{MW}=605.72$, respectively) (Figure S1).

4.2.3. Tetanus Toxoid Labeling. Sulforhodamine 101 acid chloride was coupled to the Ttx as per Titus et al. ${ }^{35}$ to obtain the $\mathrm{Ttx}$-sulforhodamine conjugate (Ttx-Rh).

4.2.4. Screenings. The first library screening was carried out at room temperature in syringes. The library was immersed in phosphate-buffered saline (PBS), $\mathrm{pH}$ 6.8. Subsequently, the beads were blocked with $10 \%$ skim milk and $2 \%$ BSA in the same buffer. The beads were washed $5 \times 1$ min with $0.1 \%$ Tween 20 in PBS (PBS-Tween) and incubated with sulforhodamide at a concentration of $3 \mu \mathrm{M}$ in PBS-Tween for $1 \mathrm{~h}$. Fluorescent beads were isolated using the COPAS BIOBEAD flow sorting equipment (Union Biometrica) following Marani et al. ${ }^{16}$ and were discarded. The nonfluorescent beads were recovered and washed with PBS-Tween before being submitted to a second screening round. For this purpose, they were blocked and washed as before and incubated with the Ttx-Rh at a concentration of $3 \mu \mathrm{M}$ in PBS-Tween for $1 \mathrm{~h}$. The beads were then thoroughly washed with PBS-Tween $(5 \times 1 \mathrm{~min})$. This time, fluorescent beads were isolated and recovered using the COPAS BIOBEAD under the same conditions as above. Selected beads were 
washed with acetic acid $(\mathrm{AcOH}) /$ acetonitrile $(\mathrm{MeCN}) / \mathrm{H}_{2} \mathrm{O}$ $(3: 4: 3)(2 \times 15 \mathrm{~min})$ to eliminate the adsorbed protein and then subsequently immersed in $\mathrm{MeCN}(5 \times 1 \mu \mathrm{L}), \mathrm{CH}_{2} \mathrm{Cl}_{2}(5$ $\times 1 \mu \mathrm{L})$ and air-dried. The peptides were then cleaved from the beads using ammonia vapor as in Martinez Ceron et al. ${ }^{36}$ and analyzed by MALDI-TOF MS in a 4700 Proteomics Analyzer instrument (Applied Biosystems). The analysis was performed following Martinez Ceron et al. ${ }^{36,37}$

4.2.5. Peptide Synthesis. The peptide Ac-Leu-Arg-Val-TyrHis-Gly-Gly-Ala-Gly-Lys- $\mathrm{NH}_{2}$ (PTx1) was synthesized by Fmoc chemistry on Rink-amide resin, as described by Chan and White ${ }^{38}$ and Martínez Ceron et al. ${ }^{36,37}$ The peptide purity was determined by HPLC analysis and by mass spectrometry analysis. HPLC analysis was carried out in a Shimadzu LC20AT instrument, a photodiode array UV-vis detector (SPDM20A) instrument with an XSelect Peptide CSH reverse-phase $\mathrm{C} 18$ column $(130 \AA \times 3.5 \mu \mathrm{m} \times 5 \mu \mathrm{m})$ at $50^{\circ} \mathrm{C}$ and a linear gradient from $100 \% \mathrm{~A}$ to $100 \% \mathrm{~B}$ in $4 \mathrm{~min}$, where $\mathrm{A}=\mathrm{H}_{2} \mathrm{O}$ $(0.045 \% \mathrm{TFA})$ and $\mathrm{B}=\mathrm{MeCN}(0.036 \% \mathrm{TFA})$, at a flow rate of $1.6 \mathrm{~mL} / \mathrm{min}$. Mass spectrometry was performed as in Martinez Ceron et al. $^{36}$

4.2.6. Preparation of the Peptidyl Matrix. The affinity matrix was prepared as described by Hermanson et al. ${ }^{39,40}$ A 1 $\mathrm{mL}$ sample of PTx1 (3-fold excess) dissolved in dimethyl sulfoxide (DMSO) was added to $1 \mathrm{~mL}$ of $N$ hydroxysuccinimide(NHS)-activated agarose slurry (Pierce, Thermo Scientific). Next, the acidity was equilibrated using anhydrous triethylamine. The mix was stirred for $4 \mathrm{~h}$ at room temperature. After that, the PTxl-agarose matrix was washed with DMSO. Any remaining NHS group was blocked by addition of ethanolamine.

4.2.7. Protein Adsorption on PTx1-Agarose Matrix Assay. The performance of the peptidyl-agarose matrix was evaluated. For the chromatographic runs, samples of $100 \mu \mathrm{L}$ of the Ttx ( 8 $\mathrm{mg} / \mathrm{mL}$ ) in several adsorption buffers were loaded on the PTx1-agarose column $(5 \times 0.5 \mathrm{~cm})$ and washed with the same buffer at a flow rate of $0.25 \mathrm{~mL} / \mathrm{min}$ until the absorbance at $280 \mathrm{~nm}$ reached its basal value. Elution was then performed, at the same flow rate.

The following equilibrating buffers were assayed: (1) PBS, $\mathrm{pH} 6.8$; (2) $20 \mathrm{mM}$ sodium phosphate buffer, $0.05 \%$ Tween 20, pH 5.9; (3) $20 \mathrm{mM}$ sodium phosphate buffer, $0.05 \%$ Tween 20, pH 7; (4) $20 \mathrm{mM}$ sodium phosphate buffer, $0.05 \%$ Tween 20, pH 5.9, $100 \mathrm{mM} \mathrm{NaCl}$; (5) $100 \mathrm{mM}$ sodium bicarbonate, $\mathrm{pH}$ 9. The following elution conditions were then assayed: (1) $100 \mathrm{mM}$ Tris- $\mathrm{HCl}$ buffer, $\mathrm{pH} 8.0,0.25 \mathrm{M} \mathrm{NaCl}$ and (2) $0.1 \mathrm{M}$ sodium acetate, $\mathrm{pH} 4.5,0.5 \mathrm{M} \mathrm{NaCl}$.

4.2.8. Determination of the Ttx Adsorption Isotherm. Chromatographic matrix aliquots $(30 \mu \mathrm{L})$ were put into tubes containing $1 \mathrm{~mL}$ of pure Ttx solution at different concentrations, in duplicate, in $20 \mathrm{mM}$ sodium phosphate buffer, $0.05 \%$ Tween 20, $\mathrm{pH}$ 5.9. The suspensions were agitated for $4 \mathrm{~h}$ at $24{ }^{\circ} \mathrm{C}$ to reach equilibrium. Protein concentration was determined with a Bradford reagent. ${ }^{22}$ The equilibrium concentration of the Ttx bound to the matrix $\left(q^{*}\right)$ was calculated as the total amount of the Ttx present at the beginning of the experiment minus the amount remaining in the soluble phase at equilibrium $\left(c^{*}\right)$. A one-to-one Langmuir binding model was used to calculate $q_{\mathrm{m}}$ and $K_{\mathrm{d}}$, as described by Chase, ${ }^{41}$ using the SigmaPlot 2012 regression program (SPSS, Inc.).

4.2.9. PTX1 Affinity Chromatography of the Formaldehyde-Treated C. tetani Culture Supernatant. Form- aldehyde-treated samples $(2.35 \mathrm{~mL})$ were preconditioned with adsorption buffer in a PD-10 (Sephadex G-25) desalting column before being loaded onto the peptidyl column. One $\mathrm{mL}$ of this desalted sample $(2.3 \mathrm{mg} / \mathrm{mL}$ total protein $)$ was loaded on the PTxl-agarose column and then washed with the same buffer at a flow rate of $0.25 \mathrm{~mL} / \mathrm{min}$ until the absorbance at $280 \mathrm{~nm}$ reached its basal value. Finally, the bound proteins were eluted with $3 \mathrm{~mL}$ of elution buffer, at the same flow rate.

4.2.10. Sodium Dodecyl Sulfate Polyacrylamide Gel Electrophoresis (SDS-PAGE). SDS-PAGE was performed as per Laemmli ${ }^{42}$ and stained with colloidal Coomassie Blue ${ }^{43}$ and Silver ${ }^{44}$ (Figure 4) following the standard procedure. Densitometric quantification of gels was performed with a BioRad GS-800 densitometer and the Image Quant TL equipment.

4.2.11. Protein Identification from SDS-PAGE Bands. SDSPAGE stained with colloidal Coomassie Blue G-250 was performed on the pass-through and elution fraction samples. The latter showed a band at $\sim 150 \mathrm{kDa}$ and another at $\sim 100$ $\mathrm{kDa}$. Fragments of the two bands were analyzed by peptide mapping analysis and mass spectrometry identification.

The methodology consisted of washing the SDS gel bands with ammonium bicarbonate $\left(25 \mathrm{mM} \quad \mathrm{NH}_{4} \mathrm{HCO}_{3}\right)$ and $\mathrm{MeCN}$. The samples were then reduced (10 mM DTT, 30 min at $56^{\circ} \mathrm{C}$ ) and alkylated ( $55 \mathrm{mM}$ iodoacetamide, $21^{\circ} \mathrm{C}$ for $30 \mathrm{~min}$ in the dark). Next, they were digested with porcine trypsin ( $80 \mathrm{ng} / \mathrm{sample}, 37^{\circ} \mathrm{C}$ overnight). Finally, the resulting peptides were extracted from the gel using $10 \%$ formic acid (FA) and $\mathrm{MeCN}$ and then dried in a speed vacuum centrifuge. A nanoAcquity chromatographer (Waters) coupled to an LTQ-Orbitrap Velos (Thermo Scientific) mass spectrometer was used to identify the peptide sequences. The samples were resuspended in $1 \% \mathrm{FA}$, and aliquots were injected for chromatographic separation in a C18 reverse-phase capillary column $(75 \mu \mathrm{m} \times 25 \mathrm{~cm}$, nanoAcquity, $1.7 \mu \mathrm{m} \mathrm{BEH}$ column, Waters). The gradient used for the elution of the peptides was 1 to $40 \%$ B in 25 min followed by a gradient from 40 to $60 \%$ B in $5 \mathrm{~min}$ (A, $0.1 \% \mathrm{FA}$; B, $100 \% \mathrm{MeCN}$ and $0.1 \% \mathrm{FA}$ ), at a flow rate of $250 \mathrm{~nL} / \mathrm{min}$.

Eluted peptides were subjected to electrospray ionization in an emitter needle (PicoTip, New Objective) with an applied voltage of $2000 \mathrm{~V}$. Peptide masses $(\mathrm{m} / z$ 300-1700) were analyzed in the data-dependent mode, where a full-scan MS was acquired in the Orbitrap with a resolution of 60,000 FWHM at $400 \mathrm{~m} / z$. The 10 most abundant peptides (minimum intensity of 500 counts) were selected from each MS scan and then fragmented in the linear ion trap using a CID (38\% normalized collision energy) with helium as the collision gas. The scan time settings were $250 \mathrm{~ms}$ (1 microscan) for MSand and $120 \mathrm{~ms}$ for MSn. The software Thermo Proteome Discoverer (v.1.4.1.14) with Sequest HT as the search engine and the UniProt (v. 19/9/2016) public database were used.

\section{ASSOCIATED CONTENT}

\section{Supporting Information}

The Supporting Information is available free of charge at https://pubs.acs.org/doi/10.1021/acsomega.1c01814.

Results of the conversion of sulforhodamine 101 acid chloride to the corresponding sulfonamide with ammonium vapor; amino acid sequences of peptides on beads that interacted with $\mathrm{Rh}$ and with the $\mathrm{Ttx}-\mathrm{Rh}$ 
and the analysis of the frequency data for amino acids found in positions of the peptides identified by screening of the peptide library with $\mathrm{Rh}$ and the Ttx-Rh; HPLC purity and mass spectrum showing the signal of the peptide PTx1 (Ac-Leu-Arg-Val-Tyr-His-Gly-Gly-AlaGly-Lys- $\mathrm{NH}_{2}$ ) (PDF)

\section{AUTHOR INFORMATION}

\section{Corresponding Authors}

María C. Martínez Ceron - Facultad de Farmacia y Bioquímica, Cátedra de Biotecnología, Universidad de Buenos Aires, 1113 Buenos Aires, Argentina; Instituto de Nanobiotecnología (NANOBIOTEC), Universidad de Buenos Aires (UBA) - Consejo Nacional de Investigaciones Cientificas y Técnicas (CONICET), 1113 Buenos Aires, Argentina; (1) orcid.org/0000-0002-5478-0976; Phone: +54 11 5287-4671; Email: camartinez@ffyb.uba.ar Osvaldo Cascone - Facultad de Farmacia y Bioquímica, Cátedra de Biotecnología, Universidad de Buenos Aires, 1113 Buenos Aires, Argentina; Instituto de Nanobiotecnología (NANOBIOTEC), Universidad de Buenos Aires (UBA) Consejo Nacional de Investigaciones Científicas y Técnicas (CONICET), 1113 Buenos Aires, Argentina; Instituto Nacional de Producción de Biológicos, ANLIS "Dr. Carlos G. Malbrán”, 1282 Buenos Aires, Argentina; Email: ocasco@ ffyb.uba.ar

\section{Authors}

Lucía Ávila - Instituto Nacional de Producción de Biológicos, ANLIS "Dr. Carlos G. Malbrán", 1282 Buenos Aires, Argentina

Silvana L. Giudicessi - Facultad de Farmacia y Bioquímica, Cátedra de Biotecnología, Universidad de Buenos Aires, 1113 Buenos Aires, Argentina; Instituto de Nanobiotecnología (NANOBIOTEC), Universidad de Buenos Aires (UBA) Consejo Nacional de Investigaciones Científicas y Técnicas (CONICET), 1113 Buenos Aires, Argentina

Juan M. Minoia - Facultad de Farmacia y Bioquímica, Cátedra de Biotecnología, Universidad de Buenos Aires, 1113 Buenos Aires, Argentina; Instituto de Nanobiotecnología (NANOBIOTEC), Universidad de Buenos Aires (UBA) Consejo Nacional de Investigaciones Científicas y Técnicas (CONICET), 1113 Buenos Aires, Argentina

Matías Fingermann - Instituto Nacional de Producción de Biológicos, ANLIS "Dr. Carlos G. Malbrán”, 1282 Buenos Aires, Argentina; CONICET, 1425 Buenos Aires, Argentina

Silvia A. Camperi - Facultad de Farmacia y Bioquímica, Cátedra de Biotecnología, Universidad de Buenos Aires, 1113 Buenos Aires, Argentina; Instituto de Nanobiotecnología (NANOBIOTEC), Universidad de Buenos Aires (UBA) Consejo Nacional de Investigaciones Científicas y Técnicas (CONICET), 1113 Buenos Aires, Argentina

Fernando Albericio - Institute for Advanced Chemistry of Catalonia (IQAC-CSIC), 08034 Barcelona, Spain; CIBER$B B N$, Networking Centre on Bioengineering, Biomaterials and Nanomedicine, Department of Organic Chemistry, University of Barcelona, 08028 Barcelona, Spain; School of Chemistry \& Physics, University of Kwazulu-Natal, 4001 Durban, South Africa; (1) orcid.org/0000-0002-8946-0462

Complete contact information is available at: https://pubs.acs.org/10.1021/acsomega.1c01814

\section{Author Contributions}

The manuscript was written through contributions of all authors. All authors have given approval to the final version of the manuscript.

\section{Funding}

This work was partially supported by the Ministerio de Ciencia, Tecnologia e Innovación Productiva de la República Argentina (PICT-2016-0751 and PICT-2018-00498) and the Universidad de Buenos Aires (20020170100030BA). M.C.M.C., S.L.G., M.F., S.A.C., and O.C. are researchers of the CONICET.

\section{Notes}

The authors declare no competing financial interest.

\section{ABBREVIATIONS}

COPAS, complex object parametric analyzer and sorter $\mathrm{BIOBEAD}$ flow sorting equipment (Union Biometrica); MALDI MS/MS, matrix-assisted laser desorption/ionization tandem mass spectrometry; PTx1, peptide Tx1 (Ac-Leu-ArgVal-Tyr-His-Gly-Gly-Ala-Gly-Lys); Ttx, tetanus toxoid; Tt, tetanus toxin; GMPs, good manufacturing practices; DCR, divide-couple-recombine; SPPS, solid-phase peptide synthesis; BSA, bovine serum albumin; HMBA-CM, hydroxymethylbenzamide-ChemMatrix; TBTU, $N$-[(1H-benzotriazol-1yl)(dimethylamino)methylene]-N-methylmethanaminium tetrafluoroborate $\mathrm{N}$-oxide; DMAP, 4-(,$N$-dimethylamino)pyridine; CHCA, $\alpha$-cyano-4-hydroxycinnamic acid; DIPCDI, 1,3-diisopropylcarbodiimide; DIPEA, N,N-diisopropylethylamine; TIS, triisopropylsilane; PBS, phosphate-buffered saline; $\mathrm{Rh}$, sulforhodamine; Ttx-Rh, Ttx-sulforhodamine conjugate; $\mathrm{AcOH}$, acetic acid; $\mathrm{MeCN}$, acetonitrile; TOF, time of flight; NHS, $N$-hydroxysuccinimide; DMSO, dimethyl sulfoxide; $q^{*}$, equilibrium concentration of Ttx bound to the matrix; $c^{*}$, total amount of $\mathrm{Ttx}$ present at the beginning of the experiment minus the amount remaining in the soluble phase at equilibrium; $q_{\mathrm{m}}$, maximum adsorption capacity; SDS-PAGE, sodium dodecyl sulfate polyacrylamide gel electrophoresis; FA, formic acid; C. tetani, Clostridium tetani

\section{REFERENCES}

(1) Stojićević, I.; et al. Tetanus toxoid purification: Chromatographic procedures as an alternative to ammonium-sulphate precipitation. J. Chromatogr., B: Anal. Technol. Biomed. Life Sci. 2011, 879, 22132219.

(2) Chandani, P.; Kashyap, T. Production, Optimization of Detoxification and Ammonium Sulphate Precipitation of Ultrafiltered Tetanus Toxin. Recent Res. Sci. Technol. 2011, 3.

(3) Mao, H. H.; Chao, S. Advances in Vaccines. Adv. Biochem. Eng./ Biotechnol. 2020, 171, 155-188.

(4) Brgles, M.; et al. Optimization of tetanus toxoid ammonium sulfate precipitation process using response surface methodology. Prep. Biochem. Biotechnol. 2016, 46, 695-703.

(5) Relyveld, E. H.; Bizzini, B.; Gupta, R. K. Rational approaches to reduce adverse reactions in man to vaccines containing tetanus and diphtheria toxoids. Vaccine 1998, 16, 1016-1023.

(6) Giudicessi, S. L.; et al. Simple method to assess stability of immobilized peptide ligands against proteases. J. Pept. Sci. 2017, 23, 685-692.

(7) Huang, P. Y.; Carbonell, R. G. Affinity purification of proteins using ligands derived from peptide libraries. Biotechnol. Bioeng. 1995, 47, 288-297.

(8) Barredo, G. R. et al. Design of affinity chromatography peptide ligands through combinatorial peptide library screening. in Methods in Molecular Biology 2178, 217-243 (Humana Press Inc., 2021). 
(9) Camperi, S. A.; et al. Peptide affinity chromatography based on combinatorial strategies for protein purification. Methods Mol. Biol. 2014, 1129, 277-302.

(10) Furka, A.; Sebestyén, F.; Asgedom, M.; Dibó, G. General method for rapid synthesis of multicomponent peptide mixtures. Int. J. Pept. Protein Res. 1991, 37, 487-493.

(11) Lam, K. S.; et al. A new type of synthetic peptide library for identifying ligand-binding activity. Nature 1991, 354, 82-84.

(12) Christensen, C.; Groth, T.; Bruun Schiødt, C.; Tækker Foged, N.; Meldal, M. Automated Sorting of Beads from a "One-Bead-TwoCompounds" Combinatorial Library of Metalloproteinase Inhibitors. QSAR Comb. Sci. 2003, 22, 737-744.

(13) Lam, K. S.; Lebl, M. Streptavidin and avidin recognize peptide ligands with different motifs. Immunomethods 1992, 1, 11-15.

(14) Lam, K. S.; Wade, S.; Abdul-Latif, F.; Lebl, M. Application of a dual color detection scheme in the screening of a random combinatorial peptide library. J. Immunol. Methods 1995, 180, 219223.

(15) Rozinov, M. N.; Nolan, G. P. Evolution of peptides that modulate the spectral qualities of bound, small-molecule fluorophores. Chem. Biol. 1998, 5, 713-728.

(16) Marani, M. M.; Martínez Ceron, M. C.; Giudicessi, S. L.; de Oliveira, E.; Côté, S.; Erra-Balsells, R.; Albericio, F.; Cascone, O.; Camperi, S. A. Screening of one-bead-one-peptide combinatorial library using red fluorescent dyes. Presence of positive and false positive beads. J. Comb. Chem. 2009, 11, 146-150.

(17) Martínez-Ceron, M. C.; et al. Two-stage screening of combinatorial peptide libraries. Application to bovine serum albumin ligand selection. Rev. CENIC, Cienc. Biol. 2015, 46, 77-86.

(18) Kodadek, T.; Bachhawat-Sikder, K. Optimized protocols for the isolation of specific protein-binding peptides or peptoids from combinatorial libraries displayed on beads. Mol. BioSyst. 2006, 2, $25-35$.

(19) Lavoie, R. A., Di Fazio, A., Carbonell, R. G., Menegatti, S. Multiplexed competitive screening of one-bead-one-component combinatorial libraries using a ClonePix 2 colony sorter. Int. J. Mol. Sci. 20, (2019), DOI: 10.3390/ijms20205119.

(20) Comellas, G.; Kaczmarska, Z.; Tarragó, T.; Teixidó, M.; Giralt, E. Exploration of the One-Bead One-Compound Methodology for the Design of Prolyl Oligopeptidase Substrates. PLoS One 2009, 4, No. e6222.

(21) Saberi-Bosari, S.; et al. Affordable Microfluidic Bead-Sorting Platform for Automated Selection of Porous Particles Functionalized with Bioactive Compounds. Sci. Rep. 2019, 9, 7210.

(22) Bradford, M. M. A rapid and sensitive method for the quantitation of microgram quantities of protein utilizing the principle of protein-dye binding. Anal. Biochem. 1976, 72, 248-254.

(23) Thaysen-Andersen, M.; Jørgensen, S. B.; Wilhelmsen, E. S.; Petersen, J. W.; Højrup, P. Investigation of the detoxification mechanism of formaldehyde-treated tetanus toxin. Vaccine 2007, 25, 2213-2227.

(24) Przedpelski, A.; Tepp, W. H.; Pellett, S.; Johnson, E. A.; Barbieri, J. T. A novel high-potency tetanus vaccine. MBio 2020, 11, $1-12$.

(25) Dijksteel, G. S., Ulrich, M. M. W., Middelkoop, E., Boekema, B. K. H. L. Review: Lessons Learned From Clinical Trials Using Antimicrobial Peptides (AMPs). Front. in Microbiol. 12, (2021), DOI: $10.3389 /$ fmicb.2021.616979.

(26) Brinckerhoff, L. H.; Kalashnikov, V. V.; Thompson, L. W.; Yamshchikov, G. V.; Pierce, R. A.; Galavotti, H. S.; Engelhard, V. H.; Slingluff, C. L., Jr. Terminal modification inhibit proteolytic degradation of an immunogenic MART-1 27-35 peptide: implications for peptide vaccines. J. Cancer 1999, 83, 326-334.

(27) Ree, R.; Varland, S.; Arnesen, T. Spotlight on protein Nterminal acetylation. Exp. Mol. Med. 2018, 50, 1-13.

(28) Kim, K. H.; Seong, B. L. Peptide amidation: Production of peptide hormonesin vivo and in vitro. Biotechnol. Bioprocess Eng. 2001, $6,244-251$
(29) Arispe, N.; Carlos Diaz, J.; Flora, M. Efficiency of HistidineAssociating Compounds for Blocking the Alzheimer's $\mathrm{A} \beta$ Channel Activity and Cytotoxicity. Biophys. J. 2008, 95, 4879-4889.

(30) Michiels, T. J. M. et al. Degradomics-Based Analysis of Tetanus Toxoids as a Quality Control Assay. Vaccines 8, (2020), DOI: $10.3390 /$ vaccines8040712.

(31) Avila, L.; Cascone, O.; Biscoglio, M.; Fingermann, M. An effective, simple and low-cost pretreatment for culture clarification in tetanus toxoid production. Prep. Biochem. Biotechnol. 2018, 48, 808814.

(32) Möller, J., Kraner, M. E., Burkovski, A. More than a toxin: Protein inventory of Clostridium tetani toxoid vaccines. Proteomes 7 , (2019), DOI: 10.3390/proteomes7020015.

(33) Michiels, T. J. M.; et al. Novel Formaldehyde-Induced Modifications of Lysine Residue Pairs in Peptides and Proteins: Identification and Relevance to Vaccine Development. Mol. Pharmaceutics 2020, 17, 4375-4385.

(34) Alsarraf, H.; et al. Biophysical comparison of diphtheria and tetanus toxins with the formaldehyde-detoxified toxoids, the main components of diphtheria and tetanus vaccines. Virulence 2017, 8, $1880-1889$.

(35) Titus, J. A.; Haugland, R.; Sharrow, S. O.; Segal, D. M. Texas red, a hydrophilic, red-emitting flourophore for use with flourescein in dual parameter flow microfluorometric and fluorescence microscopic studies. J. Immunol. Methods 1982, 50, 193-204.

(36) Martínez-Ceron, M. C.; et al. Sample preparation for sequencing hits from one-bead-one-peptide combinatorial libraries by matrix-assisted laser desorption/ionization time-of-flight mass spectrometry. Anal. Biochem. 2010, 400, 295-297.

(37) Martínez-Ceron, M. C.; et al. Affinity chromatography based on a combinatorial strategy for rerythropoietin purification. ACS Comb. Sci. 2011, 13, 251-258.

(38) Chan, W. C.; White, P. D. Basic procedures. in Fmoc Solid Phase Peptide Synthesis; Oxford University Press.: 41-76 (2000).

(39) Hermanson, G. T.; Mallia, A. K.; Smith, P. K. Immobilized affinity ligand techniques; (Academic Press: 1992).

(40) Hermanson, G. Immobilization of Ligands on Chromatography Supports. in Bioconjugate Techniques; 589-740 (2013). doi: DOI: 10.1016/B978-0-12-382239-0.00015-7

(41) Chase, H. A. Prediction of the performance of preparative affinity chromatography. J. Chromatogr. A 1984, 297, 179-202.

(42) Laemmli, U. K. Cleavage of Structural Proteins during the Assembly of the Head of Bacteriophage T4. Nature 1970, 227, 680685.

(43) Dyballa, N.; Metzger, S. Fast and sensitive colloidal Coomassie G-250 staining for proteins in polyacrylamide gels. J. Visualized Exp. 2009, DOI: $10.3791 / 1431$.

(44) Chevallet, M.; Luche, S.; Rabilloud, T. Silver staining of proteins in polyacrylamide gels. Nat. Protoc. 2006, 1, 1852-1858. 